\title{
REVIEW
}

\section{Exploring coproduction process and outcomes in public service delivery: A systematic review}

\author{
Xuan Tu \\ Department of Public Administration, Jiangsu Administration Institute, Nanjing 210009, China
}

\section{Check for updates}

Correspondence to: Xuan Tu, Department of Public Administration, Jiangsu Administration Institute, Nanjing 210009, China; E-mail: vivianpink912@163.com

Received: December 31, 2021;

Accepted: January 30, 2022;

Published: February 5, 2022.

Citation: Tu X. Exploring coproduction process and outcomes in public service delivery: A systematic review. Soc Work Soc Welf, 4(1): 185-196. https://doi.org/10.25082/SWSW.2022.01.003

Copyright: (C) 2022 Xuan Tu. This is an open access article distributed under the terms of the Creative Commons Attribution License, which permits unrestricted use, distribution, and reproduction in any medium, provided the original author and source are credited.

\begin{abstract}
This article examines the critical factors and outcomes of coproduction in public service delivery. Three research questions are posed: What is the role of citizens in coproduction? What are the critical factors of coproduction? What are the outcomes of coproduction? The study aims to contribute to a deeper understanding of the impact of coproduction by undertaking a systematic review. Traditional academic reviews are departed by examining policy and practice evidence that is drawn from 56 worldwide cases. Outcomes are identified that mainly concern the enhanced capacity of both organizations and individual participants, improved effectiveness of services, increased citizen engagement and citizen satisfaction. Evaluation of our review evidence is used to articulating a coproduction model that can inform theoretical developments in advancing coproduction research. In summary, it is suggested that coproduction can be a viable strategy in public services depending on the conditions and circumstances of the context Implications and future research agenda are provided in conclusion.
\end{abstract}

Keywords: coproduction, public services, citizens, service delivery

\section{Introduction}

One of the consistent features of effective coproduction is that those who have been receiving services are explicitly told that they have something to give back, to other people or to services themselves [1,2]. There are examples of residents forming street watch groups to build a safer environment; of parents changing their way of educating their children, and of children participating in cultural activities for effective learning. What is demonstrated from these examples is that we see a change in services that build on what people can do in order to make a way for citizens to live a better life. This change in services has been fueled by "opening up new possibilities and opportunities for active participation in various service activities while increasing the awareness of issues facing societies and providing a channel for action" [3]. Transformation in public service delivery enlightened the desire of citizens to be more involved in making decisions about their lives in public services. Important in the concept of coproduction is an emphasis on an equal and reciprocal relationship between professionals and people using services $[4,5]$. The fact that citizens' needs continue to rise is not due to a failure to consult or conduct opinion research, but is typically seen as a failure to ask people for their help and to draw on experiences they have [6]. This is the key insight of coproduction, which is central to the process of public service delivery. It is seen across many service areas that more specialized and personalized services rely on an underpinning operating system that consists of family, neighborhood, community and civil society $[6,7]$. The consequence is that citizens are becoming part of the services and their capabilities are increasingly recognized through their lived experience and participation.

Coproduction practices in public services are increasingly recognized. However a wellarticulated framework of coproduction seems lacking in literature, which is essential to improve future coproduction research. There are few scholarly studies that explicitly examine critical factors and outcomes of coproduction of public services [8-10]. Given these research gaps the following questions are posed: What is the role of citizens in coproduction? What are the determinants of coproduction? What are the outcomes of coproduction? In answer these questions it starts to explore a coproduction process based on empirical evidence from worldwide practices by way of a systematic review. The review, thereby, aims to strengthen and enhance current understanding of coproduction impact on public services.

Two contributions are made to the literature. First, it is among the few studies that undertake a holistic view by integrating the evidence from worldwide cases. This review has the potential 
to articulate a coproduction framework and provide lessons suggesting theoretical endeavors of coproduction research and the wider field of public services in terms of the design and management. Second, a critical assessment of the findings of reviewed cases can inform the current state of coproduction practices, thus build on the strengths of existing evidence to take coproduction research forward.

This article is organized as follows. In the next section perspectives of conceptualizing coproduction are presented. Then it reports the methods of conducting this systematic review. The nature of cases reviewed are described, their source, the selection criteria and coding strategy. The findings point toward articulating a coproduction model that can potentially inform theoretical developments in this field. First, it finds three roles that citizen play in coproducing public services: co-commissioner, co-deliverer and co-assessor. Second, it identifies four factors enabling coproduction including planning, establishing partnerships and direct participation. Third, it analyzes the values created from a coproduction process, which are critical to service outcomes. Fourth, the service output/outcomes are discussed and directions for future research are provided.

\subsection{Understanding coproduction}

Coproduction is about "delivering public services in an equal relationship between professionals, people using services, their families and their neighbors" [2]. It is regarded as a possible approach to improving public services by utilizing society's resources. The emphasis is on the joint delivery that involves both public service agents and citizens [11,12]. A widely discussed definition of Ostrom utilizes the concept of coproduction as "the process through which inputs used to produce a good or service are contributed by individuals who are not "in" the same organization". It implies an active role that citizens can play in the provision of services. With reference to the contribution of citizens, discussions in literature provide some explicit points that refer to long-term relationships between professionals and service users [4]. The active inputs of service users and citizens can potentially shape the service that they receive. This is a distinct feature of coproduction which extends beyond the boundaries of traditional public service delivery, involving a reciprocal process. This feature indicates that it is not enough to just receive a service; effective coproduction in practice carries a positive impact on service users and citizens which occurs outside an organizational context. In addition, the inputs by service users and citizens may affect the overall delivery of a service, which will eventually shape the performance of the service delivered.

\subsection{The role of citizens: Evidence from literature}

When we talk about citizens in public services, we conceive them as people who receive the services delivered to them [12]. In coproduction of public services, there is variation in the stages at which citizens play a role that reflects a wide range of patterns of participation. In this article, the discussion of citizens is at the most general sense in public service delivery. It is true though, citizens can be residents, service users, or even immigrants. They may form different groups depending on specific circumstances, thus the import of coproduction may vary. This needs future exploration. However, the focus here is upon how citizens has been engaged in coproduction and the impact. Sharp (1980) provides an example of curbside garbage collection where residents willingly devote their time and experiences to removing snow on major city streets in order to build a clean and safe environment. Pestoff (2006) [12] introduces childcare services in European countries with the involvement of parents, staff and public authorities. Frieling et al. (2014) [13] examine resident engagement in neighborhood security programs These studies have expanded the empirical knowledge about coproduction in terms of the role of participants and the range of participation. In such a coproduction process, the interdependence of professionals and citizens result in opportunities built upon the capacity of both organizations and individuals to create approaches to service improvement [14].

There are also studies that have examined a number of service areas in coproduction and employed methods such as surveys and experiments [9]. These studies examine aspects of coproduction in delivery of services such as safety, education and health. Results from these studies provide a more diverse evidence base that takes coproduction research forward. Given an increased number of studies on this topic, there remain a number of issues on which elements and processes of coproduction are not clear. If we employ a broad definition of coproduction in which both professionals and citizens' efforts are utilized, there are specific aspects of a service delivery process which requires a richer understanding of coproduction. The specific aspects concern the types of coproduction, its influential factors and service outcomes. As more debates have been involved in deepening current understanding of the theme, there is a need to further 
examine some of the fundamental constructs of coproduction in public services.

\subsection{Specific elements about coproduction}

The engagement of citizens in coproduction has reflected a number of elements, central to a coproduction process. One element is introduced in Park's study: an interactive process between professionals and citizens. Another element, which is frequently discussed in literature is the voluntary action performed by citizens $[5,15]$. The emphasis on this element is engaged with the recognition that to some degree, coproduction is inherent in a service. This does not mean that citizens cannot be active in the process of delivery; citizens have choices to engage in or not. The fundamental question, we need ask is what can be actually taken as a coproduction practice. Early research has informed us that the concept of coproduction involves three main elements, understood as professionals, citizens and action [11]. This allows a high flexibility in interpreting the theme. However, the original conception of coproduction literature may not apply to every practice as time changes. Recent work on coproduction is empirically keen on understanding the process of coproduction, which provide insights into the interaction between professionals and citizens [13]. Given these insights incorporated into ongoing coproduction research, it is important to capture the valid points about this theme, the core elements and relevant contexts as well. Therefore, this article takes a recent definition which perceives coproduction as a relationship between professionals and citizens that requires a direct and active contribution from these citizens to the work of the organizations.

\section{Methods}

The aim of this systematic review is to locate and synthesize coproduction research on questions of its critical factors and outcomes, thereby advancing our understanding of the general impact of coproduction on society. The advantage of conducting a systematic review lies in its organized, transparent and replicable procedures at each step in the process [16]. The aim is to explore the process of coproduction through identifying its influential factors and outcomes Given not sufficient evidence on this theme generated from existing literature, it takes policy and practice evidence from institutions that promote research on public services and coproduction in particular: Governance International, 2020 Public Trust and Nesta. These organizations represent exemplars of coproduction practices with an expertise in conducting evidence-based studies with a strong focus on coproduction in public services. This search was conducted in June 2014 and resulted in 56 eligible cases. The rationale is that first, the cases are presented with a focus on coproduction of public services; Second, the cases are presented with a clear goal and process and this makes it possible to analyze; Third, the cases included all address outcomes of coproduction which makes the sample consistent and comparable. Limitation of the case base is also recognized given the dataset is biased and could not cover all cases of coproduction.

\subsection{Coding}

Full-texts of included cases are extracted as the primary source for the review. A list of studies in this review is available online upon request (it includes the case summary here to facilitate the review process, see in Table 1). Tables are used to maintain the main content of each case, which provides a systematic and consistent record of information from the studies in the review [17].

The coding process proceeds in two stages. The first stage is open coding. All relevant texts are taken for further evaluation. It carefully reads the texts to make sure each case engages with the concept of coproduction defined in literature. To meet the eligibility of review, each case has to be coproduction focused that involves the contribution of both professionals and citizens. The second stage is detailed coding. A coding scheme is developed that includes study characteristics, process variables and outcome variables. A basic framework of the coding scheme is established and it is summarized in Table 2 with one example introduced.

\section{Results}

\subsection{Characteristics of studies}

The cases reviewed implement coproduction of public services in different service areas. It finds from the review that 51 out of 56 cases were conducted after 2000, with 5 conducted between 1990 and 1997. 49 of the 56 cases were in based in Europe and 2 were in North 
Table 1 A brief introduction of included cases

\begin{tabular}{|c|c|c|c|c|}
\hline No. & Case & Country & Year & Service area(s) \\
\hline 1 & Supporting vulnerable adults through community coproduction & UK & 1990 & Public safety \\
\hline 2 & Making a success of community ownership & UK & 1990 & Public housing \\
\hline 3 & Caring for the needy for better outcomes & UK & 1999 & Health care \\
\hline 4 & Supporting older people: establishment of food train & UK & 1995 & Health care \\
\hline 5 & Helping patients through network building & Sweden & 1997 & Health care \\
\hline 6 & Empowering patients to achieve a better life & Sweden & 2001 & Health care \\
\hline 7 & Co-designing public services with citizens: creating Internet buses for elderly people & Finland & 2001 & Public health \\
\hline 8 & Participatory budgeting & Brazil & 2001 & Budgeting \\
\hline 9 & Facilitating people with mental illness through community coproduction & UK & 2002 & Health care \\
\hline 10 & E-citizen charter and e-portfolios & Netherlands & 2002 & High technology \\
\hline 11 & Improving health qualities through community coproduction & UK & 2002 & Health care \\
\hline 12 & Connecting older people with Internet services & UK & 2002 & High technology \\
\hline 13 & Building internet network through community coproduction & UK & 2003 & High technology \\
\hline 14 & Caring for our fellow citizens: a co-ordination action plan & Australia & 2003 & General public services \\
\hline 15 & Getting people involved in community development & UK & 2003 & Employment \\
\hline 16 & Improving public services: working with staff & Germany & 2005 & General public services \\
\hline 17 & Making positive life changes through community coproduction & UK & 2005 & Health care \\
\hline 18 & Improving safety through a coproduction strategy & Sweden & 2005 & Public safety \\
\hline 19 & A coproduction journey to deliver community-led services & Turkey & 2005 & Budgeting \\
\hline 20 & Improving the use of medicine: a co-design with elderly patients & Spain & 2006 & Elder care \\
\hline 21 & Coproducing arts and culture with children & Sweden & 2006 & Culture \\
\hline 22 & $\begin{array}{l}\text { Using crowdsourcing to making lobbying more transparent: a co-design with } \\
\text { individual citizens }\end{array}$ & France & 2007 & General public services \\
\hline 23 & Communities working for a healthier city & UK & 2007 & Health care \\
\hline 24 & From complainers to coproducers & Germany & 2007 & Environment \\
\hline 25 & Building a better community: working with people around us & Germany & 2007 & Public safety \\
\hline 26 & Improving local democracy: co-designing with local citizens & Norway & 2008 & General public services \\
\hline 27 & Raising awareness of potential harms of drinking: building a public health network & UK & 2008 & Public health \\
\hline 28 & Caring for children with complex medical conditions: a partnership model & Canada & 2009 & Childcare \\
\hline 29 & Improving the experiences of patient and staff through coproduction & UK & 2009 & Health care \\
\hline 30 & Caring for the elderly: co-designing medical services & France & 2009 & Elder care \\
\hline 31 & Nurse family partnerships building: coproducing with families & US & 2009 & Social care \\
\hline 32 & A coproduction initiative in providing online free school meals & UK & 2009 & Education \\
\hline 33 & Obesity pilots & UK & 2010 & Health care \\
\hline 34 & Expert patient program production & UK & 2010 & Health care \\
\hline 35 & Long term conditions & UK & 2010 & Health care \\
\hline 36 & Fighting for a cleaner environment: collaborating with citizens & Serbia & 2010 & Environment \\
\hline 37 & Personal budgets and personalization & UK & 2010 & Social care \\
\hline 38 & Independent living strategy & UK & 2010 & Education \\
\hline 39 & Employment and retention advancement pilots & UK & 2010 & Employment \\
\hline 40 & Anti-social behavior strategy & UK & 2010 & Public safety \\
\hline 41 & Improving the lives of people with health problems through a coproduction plan & UK & 2010 & Health care \\
\hline 42 & Improving outcomes for child, parents and society through partnership & UK & 2010 & Health care \\
\hline 43 & Community coproduction in reducing crime and improving health & UK & 2010 & Public safety and health \\
\hline 44 & Working with families with complex needs through a coproduction model & Australia & 2011 & Childcare \\
\hline 45 & Engaging with communities for a safer environment & UK & 2011 & Public safety \\
\hline 46 & Developing citizen-led service inspection & UK & 2011 & Public safety \\
\hline 47 & Citizen partnerships in coproducing public services & Japan & 2011 & Childcare \\
\hline 48 & Engaging people with learning disabilities as peer reviewers & $\mathrm{UK}$ & 2011 & Education \\
\hline 49 & Engaging volunteers in co-delivering services: protecting national history & Finland & 2011 & Culture \\
\hline 50 & Reconnecting with local people in public service delivery & Sweden & 2011 & Education \\
\hline 51 & Co-designing new products to boost local economic development & Vietnam & 2012 & Tourism \\
\hline 52 & Co-designing a new third sector funding scheme & UK & 2012 & Child and family care \\
\hline 53 & Co-designing a Dementia portal & UK & 2012 & Health care \\
\hline 54 & Facilitating integration of new immigrants into community: a coproduction practice & China & 2014 & Immigrant service \\
\hline 55 & A co-design of social care website & UK & Unknown & Social care \\
\hline 56 & Initiating citizen-centered social care: exploring new perspectives & UK & Unknown & Social care \\
\hline
\end{tabular}

Table 2 Study characteristics, process category and outcome category

\begin{tabular}{|c|c|c|c|c|c|c|}
\hline \multicolumn{3}{|c|}{ Study characteristics } & \multicolumn{3}{|c|}{ Process category } & \multirow{2}{*}{$\begin{array}{c}\text { Outcome category } \\
\text { Performance indicators }\end{array}$} \\
\hline Main topic & Service area & Country & Role of citizens & Type of coproduction & Influential factors & \\
\hline $\begin{array}{l}\text { Example 1: } \\
\text { Citizens evaluating local } \\
\text { services in Southern Italy }\end{array}$ & Public health & Italy & $\begin{array}{l}\text { Co-deliverer; } \\
\text { Co-evaluator }\end{array}$ & User coproduction & $\begin{array}{c}\text { Partnership; } \\
\text { Direct participation }\end{array}$ & $\begin{array}{l}\text { Effectiveness; } \\
\text { Satisfaction }\end{array}$ \\
\hline
\end{tabular}


America and 5 in Asia. In terms of the domain of effect, 10 cases are found at the national level, 3 at the state level and 43 at the local level. A majority of cases (54 out of 56) are conducted in a single-service setting, 28 found in health (child health, mental health and general public health services ), 7 in public safety, 3 in education, 3 in employment, 2 in budgeting, 2 in culture, 2 in environment, 2 in information technology and 7 in other service areas. Figure 1 presents the case characteristics.

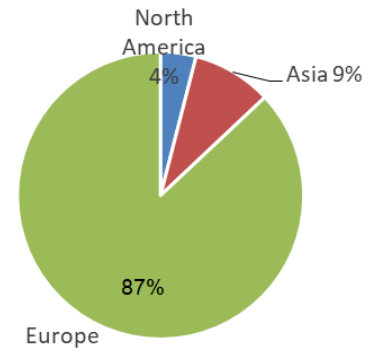

(a) Country

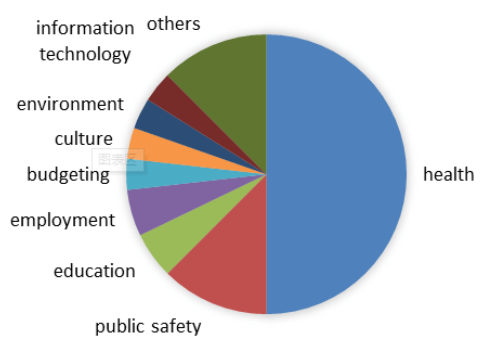

(b) Service area

Figure 1 Case characteristics

\subsection{Coproduction type and the role of citizens}

To understand how coproduction occurs in reality, explore a coproduction process, it first observes the types of coproduction and the role of citizens. Table 3 presents a contingency table regarding coproduction type identified and citizens' role through in-depth analysis of each case. The type of coproduction has been theoretically discussed in literature and it is identified based on who actually led a coproduction process.

Table 3 Coproduction type and the role of citizens

\begin{tabular}{ll}
\hline & Category \\
\hline Coproduction type & Professional coproduction \\
& User coproduction \\
& Citizen coproduction \\
\hline The role of citizens & Co-commissioner \\
& Co-deliverer \\
\hline Note: Total number higher than 56 because some case describe & Co-assessor \\
\hline
\end{tabular}

Professional coproduction is defined as a process initiated and led by employees in public sectors to improve service outcomes. For example, Koehler (2013) [18] describes a coproduction process that characterizes staff participation to improve their work efficiency and quality. User coproduction, a most prevalent type found in practice, is understood as a process where service users and professionals work together for improved outcomes of service delivery. This is a most recognized form of coproduction in public services. It is particularly prevalent in social care service delivery. Furthermore, it is found in the design of social care services, patients and families are often encouraged to take part because it is directly associated with their benefits so that their participation could actually impact the service quality. Hopwood et al. (2013) [19] and Loeffler et al. (2009) [20] present a user coproduction model in childcare services established to support parents with accessible resources to improve their children's health conditions and consequently to strengthen their confidence in living a good quality of life. Similarly, Artus and Guenoun (2012) [21], Gil and Parrado (2012) [22], Vackerberg (2013) [23] and Tholstrup (2014) [24] provide consistent examples of user coproduction of elder care services where patients and elders are engaged in a network with shared resources and knowledge where they are able to obtain a sense of caring and confidence to respond to life uncertainties and challenges. The third type found is citizen coproduction, a process where residents coproduce with professionals based on a shared vision. In most cases, citizen coproduction occurs when residents see a need to solve problems in their everyday life for example environmental protection (Rabrenovic 2011) [25] and road safety. This happens with a high motivation of ordinary people outside public organizations but successfully form collective action to make a difference in the community.

The role of citizens, manifested from the cases reviewed, tends to be multiple under different circumstances. In this article, the identification of the role is based on the stage they participate: 
degree of involvement: co-commissioner, co-deliverer and co-assessor. The rationale is built upon the work of Bovaird et al. (2011) [26] which categorized coproduction into seven types (Bovaird et al. (2011) [26] identify coproduction into seven types including co-planning, co-design, co-commissioning, co-financing, co-managing, co-delivering and co-monitoring of services). From a general sense, the in-depth analysis indicates a high involvement of citizens in co-commissioning public services and a low involvement of citizens in co-assessing public services. This findings goes consistent with current literature in which citizens' role is largely recognized in the delivery process and a considerable number of service initiatives are implemented within public organizations [27,28]. However, this does not isolate citizens from being a main part of services they experience either as service users or residents. Studies have shown that individuals are gaining the ability to internalize a perspective on community governance through participation [29]. During this process, the role of citizens has become more diverse because they could participate in different stages of service delivery. For example, citizens can be designer of a service and citizens can also be deliverer of a service [25,30].

\subsection{Coproduction processes}

Built on the coproduction type and the role of citizens identified, it further examines the conditions for coproduction, in other words, the critical factors that impact coproduction of public services. Figure 2 articulates the coproduction process analyzed from the review. Three main components are identified as essential elements of coproduction in public service delivery: planning, direct participation and partnership. These components determine coproduction occurs and how citizens engages with public services. To achieve effective coproduction, the context matters. Analyzing the cases has suggested a linkage between the conditions and the value-based factors, generated from the context that "mediate" the process of coproduction in public service delivery.

The logic running through the synthesized figure is thus. Planning is a starting point of coproduction that sets a shared vision for what is to be accomplished. Direct participation is an essential component of coproduction where stakeholders (Stakeholder in this study refers to the participation of both citizens and government organizations, including individuals and organized groups) agree to take collective action to achieve anticipated outcomes. Establishing partnerships sets the rules under which participation takes place and it provides a platform for stakeholders to discuss and seek solutions to service problems. The next section discusses each component in detail.

\begin{tabular}{|c|c|c|}
\hline & & \multirow{5}{*}{\begin{tabular}{|l|} 
Outputs/Outcomes \\
- Enhancing the capacity and confidence of citizens \\
- Enhancing the capacity of government organizations \\
- Improving the effectiveness of services \\
- Gaining greater citizen engagement \\
- Increasing citizen satisfaction
\end{tabular}} \\
\hline \multirow{3}{*}{$\begin{array}{l}\text { Process } \\
\cdot \text { Planning } \\
\cdot \text { Establishing partnerships } \\
\cdot \text { Participation }\end{array}$} & \multirow{3}{*}{\begin{tabular}{|l}
$\quad$ Values \\
$\cdot$ - Trust \\
$\cdot$ Mutual help \\
$\cdot$ Civic learning
\end{tabular}} & \\
\hline & & \\
\hline & & \\
\hline Participation & & \\
\hline
\end{tabular}

Figure 2 The coproduction process

\subsection{Planning}

Establishing a joint plan is a starting point that guides a coproduction process. A joint plan is considered as a starting point for coproduction and it is manifested in engaging citizens with the design of participation tools [22,31]. For example, Herbert and Robinson (2012) [32] and Urmson (2013) [33] present in their cases that residents are actively involved in community services from the very beginning and a joint plan could potentially create networks and communication between participants. In terms of who actually participate, the analysis shows that people do not necessarily come from a formal organization. As long as it concerns with residents' affairs, it is likely that they come along and get involved by themselves. Then they become part of the services and participate through various forms. This is a process where participants can make a difference to the service they experience because by being part of a joint plan, which may possess an influence over the service decisions they make to affect their lives.

When planning is agreed, a formal agreement would be made where consensus among actors is established in relation to specific service programmes. A considerable number of cases $(25 / 52)$ have shown that an agreement was developed to facilitate a participation processes in different service areas. There are two considerations. First, an agreement should be clear in setting out specific initiatives or programmes with a focus of what participants can do [24]. Agreeing a service design can sometimes be difficult because it takes time and negotiation between participants to establish a shared vision. In many cases, an agreement is established that explicitly states the benefits, a tool to reduce the cost of governments through coordination 
of services $[34,35]$. The second consideration is whether participants are motivated to reach an agreement if they have the skill and expertise to engage. For example, Hine-Hughes (2013) [36] examines the use of an assets-based approach to reducing community violence and points out the importance of achieving awareness and support from residents in taking necessary action. Achieving an agreement in this situation depends upon expectations of participants regarding whether the adoption of a coproduction approach will generate anticipated outcomes.

\subsection{Direct participation}

Direct participation is identified as a necessary component, an essential condition for effective coproduction. A recent systematic review argues that participation is a core component part of public service delivery, where service users play a central role in value creation for themselves and for society [37]. Analysis of the cases suggests that participation is more than a tool to get citizens involved; it is a process where citizens become part of a service with enhanced vision and where they learn to make decisions about their lives [38,39]. By examining how citizens participate, three main tools are utilized: citizen survey, citizen advisory group and voluntary citizen group. A noteworthy finding is that citizen surveys were not widely implemented in most cases, given it an evaluation tool well discussed in literature. In fact, the limited and sporadic use of citizen surveys has not allowed the full potential of surveys to be analyzed or realized [40].

The second tool of participation is forming citizen advisory groups, based on the interests of residents. These groups are primarily established by concerned citizens with an aim of improving community wellbeing through working with government organizations and other relevant agencies. For instance, Takeuchi and Loffler (2014) [41] have examined how citizen advisory groups increased local autonomy that strengthened resident participation through community coproduction. This process is a significant part of coproduction that generates a sense of collective action on community building.

The third tool is voluntary citizen groups. Different from the second tool, voluntary groups in coproduction are initiated to solve small-scale problems, most of which occur in a neighborhood. Participants form street watcher groups or emergency groups, not driven by the need of answering the "call" of local authorities, but on a shared vision of making a change to the place they live. To a certain extent, these groups, despite of which tool used, represent the interests and are highly aware of the needs of local people in order to improve the quality of services and their lives. In this sense, citizens can be ephemeral teams of neighbors attempting search and rescues, they can be community residents organizing themselves to force removal of potentially hazardous waste sites; they can also be disaster victims getting together to pressure local governments to take preparedness and action for reoccurrence of the floods and landslides they have just experienced [42].

As regard to who participate in coproduction, three types are identified: staff participation, community participation and resident participation. For instance, Koehler (2008) [18] describes staff participation in improving government policies through change management. It is characterized a process where staff of different levels are engaged in coproducing services. The outcome is delivered with an increased expectation of staff towards a changing process of management. Community participation is most prevalent in coproduction of public services. Emil and Akman (2014) [43] and Lawson et al (2014) [44] examine how community coproduction could potentially improve local infrastructure and people's lives. Based on the analysis, community participation is largely citizenresident-driven concerning daily needs and services, which provides opportunities of fact-to-face communication among participants. The third type is individual participation in coproducing public services [36,41]. Key elements of individual participation are incorporated in a series of efforts made including designing new initiatives, giving suggestions and providing support. It is observed that participation of residents in coproducing public services is helpful to arrive at a decision based not only on facts but also values [45]. Rather than perceiving participation as a tool to promote civic values, it is actually developing into a mechanism where local government provides support to facilitate in order to build strong collaborative links between citizens and government organizations.

Given direct participation being an essential element of coproduction, a further question is how could effective participation be maintained? When well-designed, coproduction is likely to succeed, a process in which people come with no authority, forming a group for effective communication, problem evaluation and decision making [46]. Facilitating direct participation is necessary as face-to-face contact between citizens and local authorities becomes frequent and it is almost impossible to isolate people in public services which they are associated with. To make this point a bit further, it is found that coproduction seems to favor small-scale participation. First, small-scale participation enables intensive communication among participants, which 
is beneficial to obtain feedback; second, small-scale participation are likely to generate more in-depth discussions; third, small-scale participation makes it feasible to trace processes for collective benefits, so that to arrive a joint view that integrates individual perspectives [47].

\subsection{Partnership}

Partnership is widely seen as one of the critical elements in solving problems by bringing actors to the table. The literature finds that the success of partnerships relies on the ability to produce better outcomes of public services [48]. In analyzing partnerships in coproduction of public services, it is found nearly $50 \%$ of the cases included indicating the importance of bringing service users and citizens and getting them to engage each other in coproducing services. Most of the times, the success of partnerships can contribute to an effective coproduction process where direct face-to-face contact takes place.

Building partnerships is crucial for tackling problems by utilizing the resources of a range of different providers and interest groups [49]. Hopwood et al (2013) [19] provides an example of building a partnership with families in coproducing health services. They describe the partnership established as a tool characterized by its focus on addressing the needs of parents and children and improving their life conditions. Furthermore, partnership demonstrated in these cases has different forms. In particular, it has three forms: the partnership between government agencies and other public organizations, the partnership between government agencies and nonprofit organizations and the partnership between government agencies and private sectors.

The first form identified is the partnership between government agencies and other public organizations. Establishing partnerships is closely related to the original plan in coproduction of public services. Participants in coproduction may expect to contribute their knowledge or time in order to fulfill a programme or project. For instance, local councils partner with public schools to promote educational programmes among students aiming at cultivating their creative learning abilities. Such a partnership is built based on a shared vision: a goal of improving creative learning of students. It requires a commitment of all participants to the process for mutual gains in order to achieve desirable coproduction outcomes.

The second form identified is the partnership between government agencies and non-profit organizations. This type of partnership is essential for participants to develop trust and create opportunities for mutual gains in a coproduction process. The trust cultivated through establishing a partnership builds on effective communication and negotiation, a necessary step for participants to develop shared understanding and consistent efforts to coproduce. It is found that sustaining this type of partnership relies on achieving a virtuous cycle between collaboration across organizations, participation and outcomes of services. In other words, the partnership between government agencies and non-profit organizations may contribute to a coproduction process when trust is developed and collaboration and participation is strengthened.

The third form identified is the partnership between government agencies and private sectors (for example enterprises). Interestingly it is found only a few cases to represent and this may be because of the diversity of goals of organizations that makes it hard to form collaboration between government departments and companies. For example, Jones (2012) [50] presents a case of community coproduction in which local councils work with residents and firms. Success of this partnership depends on clear rules and a transparent process of delivery. Both rules and the process in this case can be understood as a result of effective collaboration. However, this type of partnership is not widely practiced in cases reviewed and it is not always successful either. In fact, it takes time to cultivate the relationship of different participants; it also takes time to develop a long-term commitment to achieving desirable coproduction outcomes.

\subsection{The role of values}

Existing literature has argued that when public services are used, then value is received [51]. It is the process through which the experience of a public service in the context of people's whole-life experience. By examining the critical factors it can arrive at an articulation of a coproduction process, in which a set of values are generated. The values generated from a coproduction process encompass outputs and outcomes, that is "impacts upon those who enjoy the value or upon states of nature important to those people". It is found three prominent ones from the cases reviewed: trust, mutual-help and civic learning based on the interaction between coproducers. More broadly, society can also gain value from public services, either through their giving expression to societal values or by their addressing systemic societal issues [52]. Built on prior exploration, the analysis makes value explicit for a public service and helps evaluate the outcome of public services. The three aspects of value identified may not be absolute standards, given trust widely discussed in collaboration literature [53-56]. However, it did show that coproduction of public services connotes an active sense of adding value. It entails a wider 
range of accounts: the effectiveness of services and more importantly, the impact upon people who use and participate in those services.

Building trust among participants should embark on a coproduction strategy when a joint plan is justified. In literature, the lack of trust among stakeholders is considered as a starting point for collaboration. What is found from the cases is that trust among participants could be potentially developed throughout the process of coproduction, an important aspect that affects outcomes. Even though trust building is not explicitly discussed in the cases reviewed, it indicates the recognition of commitment of participants to achieve their goals being important to nurture trust. Another distinct aspect related to outcomes is mutual help, generated from constant face-to-face communication and strengthened relationship of participants. This is a meaningful result yielded from a coproduction process, and it comes from a direct relationship between citizen participation and effective partnerships with organizations. Cultivating mutual help in coproduction of public service depends largely on the nature of a service, most prevalent in health services [57]. For example, patients are encouraged to enter into collaboration based on a foundation of trust and a shared understanding of a health programme they are involved. Perceptions of mutual help often depend on the level of patient participation and the joint dependence of patients, doctors and local health authorities on resources. The implication of this interdependence can potentially develop civic learning in terms of knowledge, skills and action.

\subsection{Service outputs/outcomes}

Based on the exploration of a coproduction process, it then proceeds to analyze the service outputs/outcomes of such a process. Main elements are identified: enhanced capacity of organizations (including government agencies and other public organizations), enhanced capability of citizens, improved effectiveness of services, greater citizen engagement and increased citizen satisfaction.

As is reported in Figure 2, case analysis has suggested an increase in effectiveness of services being a main outcome of coproduction. Gil and Parrado (2006) [22] analyze coproduction of health services and observe improved quality of health conditions of patients involved in the programme. Hammer (2006) [58] provides a case showing co-producing art services with young people has changed children's lives positively. Some cases show an enhanced capacity of organizations and individual participants through a coproduction approach in delivering services. For instance, Tholstrup (2014) [24] finds that patients become capable in control of their own health and lives through a coproduction strategy with local hospitals. Meanwhile, many records are found presenting how citizen engagement and satisfaction are increased, given limited records found in 14 cases. Thus it cannot conclude whether coproduction of public services can actually increases the participation of citizens and their satisfaction toward the services they coproduce. Insights to this question can be strengthened through further studies to offer ample evidence about specific coproduction outcomes.

\section{Discussion and conclusion}

By conducting a systematic review of worldwide coproduction cases, this article makes an effort of unpacking public service delivery in reality and acknowledging the value creation process embedded in coproduction of public services. This marks an important endeavor in theorizing about coproduction in public services and the roles citizens make. Further, the role is predicated upon the value creation and co-creation initiatives of service users [51]. Based on a systematic review of 56 coproduction cases, the findings are largely empirical-driven that provide insights to understanding the general impact of coproduction. Exploring the critical factors has enabled us to articulate a coproduction framework that could potentially inform theoretical developments in understanding the fundamental logic of public service delivery. To move coproduction research forward, an explicit agenda is expected to continue integrating empirical findings to test out theoretical perspectives discussed in literature.

To fully realize coproduction of public services, several considerations are necessary to be addressed. In terms of the role of citizens, it is no surprising to find that citizens are increasing encouraged in take part in more and more services and the role has been widely recognized. Identification of citizen role is important to the evolution of coproduction theory. This article serves as a first step to nurturing citizen efforts in understanding public service process and how coproduction could benefit the process for long term value creation. This raised a further question of nurturing citizens' skills and capacity to enable them to maximize the positive effects of public service delivery. 
Furthermore, co-production of public services does not always generate positive outcomes and it depends on specific contexts and circumstances in which coproduction occurs. It is recognized in the article that a systematic review is limited in its sample and availability of sources. Due to the qualitative nature of the analysis, it is difficult to conclude to what extend does each factor impact on service outcomes. Answers to this question may trigger future research committed to developing the empirical testing and theory elaboration on embarking on a viable strategy of service delivery. In addition, the interaction of the actors, structures and processes within public service system is central both to the effective governance in public service delivery and to its contribution to the creation of individual and societal value. This expects further theoretical exploration and empirical research.

The systematic approach to understanding coproduction presented in this article has important implications for public service management in policy-making. First, building a common ground for coproduction is essential that involves both intrinsic and extrinsic processes of public service delivery, in which citizens and professionals play a fundamental role during these processes Second, to further implement coproduction, a pragmatic approach is needed to examine explicit forms of coproduction that links participants and societal contexts. Therefore, there is a role for both policy makers and individuals to play. Third, values will not be created automatically in a coproduction process. Rather, it requires public service practioners and service users to collaborate through joint efforts. Value creation, manifested from real life cases, has been associated with coproductive activities within public service and public policy, in which cultural elements are critical to support the process [51]. While this change requires a complex process to achieve given different policy contexts may have different circumstances.

To summarize, this article argues for a more integrated approach to enhancing current understanding of coproduction in public services, through the creation of values. It utilizes insights from public management and public policy by suggesting an emerging research agenda around a service-oriented framework for coproduction. Several themes are generated. First, the term of coproduction needs to be clearly conceptualized and validated by further research; second, outcomes of coproduction requires defined measurements by quantifiable criteria; third, further research is expected to investigate the impact of wider public service system engaging both intrinsic and extrinsic processes of coproduction. Despite widespread practices of coproduction in different countries, there remain challenges around how to sustain effective coproduction for improved service performance. Thus future research is anticipated to engage cultural, political and societal accounts to address concerned questions in order to advance theories.

\section{References}

[1] Boyte HC. The Citizen Solution: How You Can Make A Difference. Minnesota Historical Society, 2008.

[2] Boyle D, Coote A, Sherwood C, et al. Right Here, Right Now. 2010. http://b.3cdn.net/nefoundation/8678a9d67320a294b4_38m6ivak1.pdf

[3] Kannan PK and Chang AM. Beyond Citizen Engagement: Involving the Public in Co-Delivering Government Services, 2013.

[4] Bovaird T. Beyond Engagement and Participation: User and Community Coproduction of Public Services. Public Administration Review, 2007, 67(5): 846-860. https://doi.org/10.1111/j.1540-6210.2007.00773.x

[5] Alford J. Engaging Public Sector Clients: From Service-Delivery to Coproduction . New York, NY Palgrave Macmillan, 2009. https://doi.org/10.1057/9780230235816

[6] Boyle D and Harris M. The Challenge of Coproduction . London: NESTA, 2009.

[7] Needham C and Carr S. Coproduction : An Emerging Evidence Base for Adult Social Care Transformation. London: Social Care Institute for Excellence, 2009.

[8] Parrado S, Van Ryzin GG, Bovaird T, et al. Correlates of coproduction : Evidence from a five-nation survey of citizens. International Public Management Journal, 2013, 16(1): 85-112. https://doi.org/10.1080/10967494.2013.796260

[9] Jakobsen M. Can Government Initiatives Increase Citizen Coproduction? Results of A Randomized Field Experiment. Journal of Public Administration Research and Theory, 2012, 23(1): 27-54. https://doi.org/10.1093/jopart/mus036

[10] Bvaird T, Loeffler E, Yates S, et al. International survey evidence on user and community co-delivery of prevention activities relevant to public services and outcomes. Public Management Review, 2021, $1-23$. https://doi.org/10.1080/14719037.2021.1991665

[11] Parks RB, Baker PC, Kiser L, et al. Consumers as Coproducers of Public Services: Some Economic and Institutional Considerations. Policy Studies Journal, 1981, 9(7): 1001-1011. https://doi.org/10.1111/j.1541-0072.1981.tb01208.x 
[12] Pestoff V. Citizens and Coproduction of Welfare Services: Childcare in Eight European Countries. Public Management Review, 2006, 8(4): 503-519.

https://doi.org/10.1080/14719030601022882

[13] Frieling MA, Lindenberg SM and Stokman FN. Collaborative Communities through Coproduction Two Case Studies. The American Review of Public Administration, 2014, 44(1): 35-58. https://doi.org/10.1177/0275074012456897

[14] Entwistle T and Martin S. From Competition to Collaboration in Public Service Delivery: A New Agenda for Research. Public Administration, 2005, 83(1): 233-242. https://doi.org/10.1111/j.0033-3298.2005.00446.x

[15] Brudney JL. Local Coproduction of Services and the Analysis of Municipal Productivity. Urban Affairs Review, 1984, 19(4): 465-484. https://doi.org/10.1177/004208168401900405

[16] Littell JH, Corcoran J and Pillai V. Systematic Reviews and Meta-analysis. Oxford: Oxford University Press, 2008. https://doi.org/10.1093/acprof:oso/9780195326543.001.0001

[17] Boaz A, Ashby D and Young K. Systematic Reviews: What Have They Got to Offer Evidence Based Policy and Practice?. London: ESRC UK Centre for Evidence Based Policy and Practice, 2002.

[18] Koehler G. Harnessing Staff Ideas for Improving Efficiency and Quality: CAF-based Self-assessments in Hessen in Germany, 2013.

[19] Hopwood N, Dunston R and Clerke T. The Family Partnership Model in practice in New South Wales: Working With Families With Complex Needs to Make A Difference, 2013.

[20] Loffler E, Parrado S, Bovaird T, et al. Citizens and the Coproduction of Public Services. Commission Report, 2008.

[21] Artus L and Guenoun M. Ages et Vie: Personalised Care and A Richer Social Life for the Elderly In Rural France, 2012.

[22] Gil F and Parrado S. "Don't forget to take your medicine!" Improving the Use of Medicine by Elderly Patients In The Region of Madrid, 2012.

[23] Vackerberg N. The Esther Approach to Healthcare in Sweden: A Business Case for Radical Improvement, 2013.

[24] Tholstrup J. Empowering Patients to Need Less Care and Do Better in Highland Hospital, South Sweden, 2014.

[25] Rabrenovic A. Cleaning-up Serbia: Designing and Delivering A Public Campaign With Over 200,000 Volunteers, 2011.

[26] Bovaird T, Loffler E and Hine-Hughes F. From Passive Customers to Active Co-producers: The Role of Coproduction in Public Services, 2011.

[27] Milton S. Community Speedwatch Scheme in Wiltshire to Reduce Speeding and Empower Residents, 2011.

[28] Flowers R. "I can see what you can't see" - How Warwickshire County Council Involves People With Learning Disabilities As Peer Reviewers, 2013.

[29] Srensen E. Democracy and Empowerment. Public Administration, 1997, 75(3): 553-567. https://doi.org/10.1111/1467-9299.00074

[30] Kaufmann B. Falun On the Road to Becoming A 'Democracy City' in Sweden, 2013.

[31] Harju E. Go Where the People Are: The Netti-Nysse Bus in Tampere, 2013.

[32] Herbert K and Robinson T. Co-designing A Dementia Portal for Warwickshire and Coventry, 2012.

[33] Urmson J. The Network Is the Key: How KeyRing Supports Vulnerable Adults in the Community, 2013.

[34] Carr JB, Gerber ER and Lupher ER. Explaining Horizontal and Vertical Cooperation on Public Services in Michigan: The Role of Local Fiscal Capacity. In Metropolitan Affairs in Michigan, Michigan State University Press, 2009.

[35] Collins BK and Gerber BJ. Taken For Granted? Managing for Social Equity in Grant Programs. Public Administration Review, 2008, 68(6): 1128-1141. https://doi.org/10.1111/j.1540-6210.2008.00960.x

[36] Hine-Hughes F. Digital Inclusion: How Age UK Camden Helps Older People to Connect, 2013.

[37] Osborne SP and Strokosch K. Participation: Add-on or core component of public service delivery? Australian Journal of Public Administration, 2021, 1-20. https://doi.org/10.1111/1467-8500.12536

[38] Lambert T. "Drink A Little Less. See A Better You!" Social Marketing Campaign Delivered by ChaMPs Public Health Network, 2012.

[39] Laratta R. Local Economic Development Through Crafts: Co-designing New Products in Vietnam, 2013.

[40] Webb K and Hatry HP. Obtaining Citizen Feedback: The Application of Citizen Surveys to Local Governments. The Urban Institute Report, 1973.

[41] Takeuchi A and Loffler E. How Citizen Partnerships Co-produce Projects With Yamato City in Japan, 2014.

[42] Stallings RA and Quarantelli EL. Emergent Citizen Groups and Emergency Management. Public Administration Review, 1985, 45: 93-100. https://doi.org/10.2307/3135003 
[43] Emil F and Akman E. From Participatory Budgeting to Community-led Services: The Coproduction Journey of anakkale in Turkey, 2014.

[44] Lawson D, Loffler E and Maggs L. How Community Health Trainers in Manchester Enable Positive Lifestyle Changes, 2014.

[45] Gastil J. Deliberation. In Gregory J. S., John St. J. and Striphas. T. (eds.), In Communication as Perspectives on Theory pp164-73.Thousand Oaks, CA: Sage Publications, 2005.

[46] Schwarz R. The Skilled Facilitator: A Comprehensive Resource for Consultants, Facilitators, Managers, Trainers, and Coaches. San Francisco: Jossey-Bass, 2002.

[47] Lukensmeyer CJ and Brigham S. Taking Democracy to Scale: Creating a Town Hall Meeting for the Twenty-First Century. National Civic Review, 2002, 91(4): 351-366. https://doi.org/10.1002/ncr.91406

[48] Agranoff R. "Collaboration for Knowledge Learning from Public Management Networks." In L. B. Bingham and R. O'Leary (eds.), Big Ideas in Collaborative Public Management. Armonk, N.Y.: Sharpe, 2008.

[49] Lowndes V and Skelcher C. The Dynamics of Multi-organizational Partnerships: An Analysis of Changing Modes of Governance. Public Administration, 1998, 76(2): 313-333. https://doi.org/10.1111/1467-9299.00103

[50] Jones P. Witton Lodge Community Association: Making A Success of Community Ownership, 2013.

[51] Osborne SP, Nasi G and Powell M. Beyond co-production: Value creation and public services, Public Administration, 2021, 99: 641-657. https://doi.org/10.1111/padm.12718

[52] Bryson J, Sancino A, Benington J, et al. Towards a multi-actor theory of public value co-creation. Public Management Review, 2017, 19(5): 640-654. https://doi.org/10.1080/14719037.2016.1192164

[53] Alexander JA, Comfort ME and Weiner BJ. Governance in PublicPrivate Community Health Partnerships: A Survey of the Community Care Network SM Demonstration Sites. Nonprofit Management and Leadership, 1998, 8(4): 311-332. https://doi.org/10.1002/nml.8402

[54] Brinkerhoff DW. Exploring State-Civil Society Collaboration: Policy Partnerships Developing Countries. Nonprofit and Voluntary Sector Quarterly, 1999, 28(Suppl 1): 59-86. https://doi.org/10.1177/089976409902801S01

[55] Beierle TC and Konisky DM. What Are We Gaining from Stakeholder Involvement? Observations from Environmental Planning in the Great Lakes. Environment and Planning C, 2001, 19(4): 515-528. https://doi.org/10.1068/c5s

[56] Ansell C and Gash A. Collaborative Governance in Theory and Practice. Journal of Public Administration Research and Theory, 2008, 18(4): 543-571. https://doi.org/10.1093/jopart/mum032

[57] Bone T. Reducing Crime and Improving Health in NW Kilmarnock Using Community Assets, 2012.

[58] Hammer B. 'Kids Tell Pros What to Do' - Young People Co-produce Arts and Culture in Umea, Sweden, 2013. 